\title{
Effects of patch size and density on flower visitation and seed set of wild plants: a pan-European approach
}

Article

Published Version

online open

Dauber, J., Biesmeijer, J. C., Gabriel, D., Kunin, W. E., Lamborn, E., Meyer, B., Nielsen, A., Potts, S. G., Roberts, S. P., Sõber, V., Settele, J., Steffan-Dewenter, I., Teder, T. and Tscheulin, T. (2010) Effects of patch size and density on flower visitation and seed set of wild plants: a pan-European approach. Journal of Ecology, 98 (1). pp. 188-196. ISSN 00220477 doi: https://doi.org/10.1111/j.1365-2745.2009.01590.x Available at https://centaur.reading.ac.uk/6055/

It is advisable to refer to the publisher's version if you intend to cite from the work. See Guidance on citing.

To link to this article DOI: http://dx.doi.org/10.1111/j.1365-2745.2009.01590.x

Publisher: British Ecological Society

All outputs in CentAUR are protected by Intellectual Property Rights law, including copyright law. Copyright and IPR is retained by the creators or other copyright holders. Terms and conditions for use of this material are defined in the End User Agreement. 


\section{CentAUR}

Central Archive at the University of Reading

Reading's research outputs online 


\title{
Effects of patch size and density on flower visitation and seed set of wild plants: a pan-European approach
}

\author{
Jens Dauber ${ }^{1,2,8 *}$, Jacobus C. Biesmeijer ${ }^{1}$, Doreen Gabriel ${ }^{1}$, William E. Kunin ${ }^{1}$, \\ Ellen Lamborn ${ }^{2,3}$, Birgit Meyer ${ }^{4,5}$, Anders Nielsen ${ }^{2}$, Simon G. Potts ${ }^{3}$, Stuart P. M. Roberts ${ }^{3}$, \\ Virve Sõber ${ }^{6}$, Josef Settele ${ }^{7}$, Ingolf Steffan-Dewenter ${ }^{5}$, Jane C. Stout ${ }^{8}$, Tiit Teder $^{6}$, \\ Thomas Tscheulin ${ }^{2,3}$, Daniele Vivarelli ${ }^{2,9}$ and Theodora Petanidou ${ }^{2}$ \\ ${ }^{1}$ Institute of Integrative and Comparative Biology and Earth and Biosphere Institute, University of Leeds, Leeds LS2 \\ 9JT, UK; ${ }^{2}$ Laboratory of Biogeography and Ecology, Department of Geography, University of the Aegean, University \\ Hill, GR-81100 Mytilene, Greece; ${ }^{3}$ Centre for Agri-Environmental Research, University of Reading, Reading RG6 \\ 6AR, UK; ${ }^{4}$ Agroecology, Department of Crop Sciences, Georg August University, Waldweg 26, 37073 Göttingen, \\ Germany; ${ }^{5}$ Department of Animal Ecology I, Population Ecology, University of Bayreuth, Universitätsstraße 30, \\ D-95440 Bayreuth, Germany; ${ }^{6}$ Institute of Ecology and Earth Sciences, University of Tartu, Lai 40, 51005 Tartu, \\ Estonia; ${ }^{7}$ UFZ-Helmholtz Centre for Environmental Research, Department of Community Ecology, Theodor-Lieser- \\ Str. 4, D-06120 Halle (Saale), Germany; ${ }^{8}$ School of Natural Sciences, Trinity College Dublin, Dublin 2, Ireland; and \\ ${ }^{9}$ Department of Evolutionary Experimental Biology (BES), University of Bologna, Via Irnerio 42, I-40126 Bologna, Italy
}

\section{Summary}

1. Habitat fragmentation can affect pollinator and plant population structure in terms of species composition, abundance, area covered and density of flowering plants. This, in turn, may affect pollinator visitation frequency, pollen deposition, seed set and plant fitness.

2. A reduction in the quantity of flower visits can be coupled with a reduction in the quality of pollination service and hence the plants' overall reproductive success and long-term survival. Understanding the relationship between plant population size and/or isolation and pollination limitation is of fundamental importance for plant conservation.

3. We examined flower visitation and seed set of 10 different plant species from five European countries to investigate the general effects of plant populations size and density, both within (patch level) and between populations (population level), on seed set and pollination limitation.

4. We found evidence that the effects of area and density of flowering plant assemblages were generally more pronounced at the patch level than at the population level. We also found that patch and population level together influenced flower visitation and seed set, and the latter increased with increasing patch area and density, but this effect was only apparent in small populations.

5. Synthesis. By using an extensive pan-European data set on flower visitation and seed set we have identified a general pattern in the interplay between the attractiveness of flowering plant patches for pollinators and density dependence of flower visitation, and also a strong plant species-specific response to habitat fragmentation effects. This can guide efforts to conserve plant-pollinator interactions, ecosystem functioning and plant fitness in fragmented habitats.

Key-words: flower density, flower visitation, habitat fragmentation, patch area, patch density, pollen limitation, pollination, seed set

\section{Introduction}

Human-mediated landscape fragmentation, gradually leading to loss of natural and seminatural habitats, has become an increasingly common phenomenon (Kareiva \& Wennergren 1995), with subsequent declines in many components of biodiversity, including plants and their pollinators (Kearns,

*Correspondence author. E-mail: dauberj@tcd.ie
Inouye \& Waser 1998; Krauss, Steffan-Dewenter \& Tscharntke 2003). Habitat loss and degradation often leave fragments of suitable habitat containing small and isolated plant populations in a matrix of unsuitable, structurally poor landscape (Vitousek 1994; Fischer \& Stöcklin 1997). Many plant species are naturally rare and occur in small and isolated populations, but even populations of some relatively common plant species have become smaller and more isolated as a consequence of habitat alterations (Oostermeijer et al. 2000). 
For the majority of higher plants, animal-mediated pollination is essential for, or greatly enhances, seed set, but it is unclear how fragmentation of plant populations affects pollinator attraction and hence the populations' overall reproductive success (Steffan-Dewenter \& Tscharntke 1999). Several studies have shown that there is a relationship between plant population size and/or isolation and fitness (e.g. Petanidou, den Nijs \& Ellis-Adam 1991; Jennersten \& Nilsson 1993; Nielsen \& Ims 2000; Fox 2007), thus understanding this relationship is of fundamental importance for plant conservation (Leimu et al. 2006).

A reduction in pollinator attraction to small plant populations (i.e. the quantity of pollination events) can be coupled with a reduction in quality of pollination service in terms of the deposition of viable, conspecific, outcross pollen on stigmas (Rathcke 1983; Larson \& Barrett 2000; Klinkhamer \& van der Lugt 2004). Reduced pollination quality due to self-pollination and heterospecific pollen transfer (Murphy \& Aarssen 1995; Campbell \& Husband 2007; Holland \& Chamberlain 2007; Jakobsson, Padron \& Traveset 2008) can lead to pollination limitation, which again may reduce fitness in small populations (e.g. Ågren 1996; Steffan-Dewenter et al. 2006). Based on a meta-analysis of plant reproductive susceptibility to habitat fragmentation, Aguilar et al. (2006) suggested that the most prominent cause of reproductive impairment in fragmented habitats may be insufficient pollination.

Our study was motivated by previous studies' findings that plant population structure, in terms of area covered and/or flower density, may affect pollinator visitation frequency (Petanidou, Den Nijs \& Oostermeijer 1995; Kunin 1997a; Steffan-Dewenter \& Tscharntke 2002). Most studies of pollination limitation have examined the dependence on either density or extent of a plant population, with few considering both parameters in conjunction with pollinator attraction and plant fitness (e.g. Kunin 1997b; Petanidou et al. 1998; Waites \& Ågren 2004). To understand how these parameters act in concert is important for predicting when and to what extent pollen limitation occurs in plant populations (Ashman et al. 2004; Knight et al. 2005; Hegland \& Totland 2008).

In this study, we expected seed set and pollen limitation to be affected by the area and density of plant populations both within and between populations. In particular, we expected plant population area (defined as area covered by all plant individuals of the focal species occurring in a habitat fragment) to be important for at least three reasons: first, habitat fragmentation and resulting geographic isolation may limit the movement, diversity and density of pollinators, thereby reducing gene flow between plant populations (Jennersten 1988; Aizen \& Feinsinger 1994; Cunningham 2000); second, larger plant populations may be more often encountered by pollinators and support lower extinction rates of pollinators in comparison to small populations (sensu Rosenzweig 1995); third, plants in larger populations present a larger total floral display, which may improve foraging efficiency and hence make them more attractive to pollinators (Goulson 2000), and large floral displays can function as long-distance cues (Waser 1983). In addition to population area per se, the density of plants (or of flowers) within a patch may also have important consequences for pollination. If pollinators choose among aggregations of floral resources in a landscape, they may switch to species with higher floral densities (Steffan-Dewenter, Münzenberg \& Tscharntke 2001; Westphal, Steffan-Dewenter \& Tscharntke 2003). Moreover, high floral densities of a particular plant species may increase the effective constancy of pollinators, thus reducing interspecific pollen transfer and increasing the quality of pollinator visits (Kunin 1993). Within a population we expect size and density of individual patches of plants to influence both the number of pollinators attracted to a patch and their behaviour within it (Kunin 1997b), thus affecting pollination efficiency through density dependence and intraspecific competition for pollination. In turn, this variation in pollinator visitation may affect seed production.

We investigated the effects of plant population structure at both the population (i.e. all plant individuals of a focal species occurring in a habitat fragment) and the patch level (i.e. distinct aggregations of the focal plant species within a population). We examined, using standardized protocols, flower visitation and seed set of 10 different plant species from five European countries spanning Mediterranean, continental, Atlantic and boreal biomes. We were primarily interested in looking for general trends in the response of pollinators and pollination services to the spatial configuration of flowering plants. Our aim was to test the hypothesis that there is a fundamental underlying mechanism affecting the relationship between pollination success and the spatial structuring of plant communities, which is based on attractiveness of patches of flowering plants for pollinators and the flower density dependence of pollinator visitation. Therefore, we were interested in the overall nature of general trends rather than the specific values for each plant species. By studying multiple species situated in different habitats and biogeographic regions we were able to test the generality of the expected fitness effects of spatial plant population structure. Specifically, we addressed the following questions: (i) Is flower visitation affected by the size and/or the density of the floral display measured at the patch and population level? (ii) Do these effects explain variation in seed set of the plants? (iii) Is there evidence for pollen limitation in the plant species studied and can this be related to the size and density measures at the patch and population level? (iv) Are the effects of spatial plant population structure on seed set more prominent in self-incompatible than in self-compatible plant species, as pollen limitation might be especially detrimental in self-incompatible, obligate out-crossing plant species which entirely depend on pollinators for sexual reproduction (Leimu et al. 2006)?

\section{Materials and methods}

\section{SELECTION OF PLANT SPECIES AND STUDY REGIONS}

We selected 10 plant species from five European countries comprising four bioclimatic zones (Table 1). The species are all insect-pollinated, grow in remnant and/or fragmented semi-natural habitats (Table 1), and belong to five different plant families: Boraginaceae (Echium 
Table 1. Species characteristics, study regions and habitats

\begin{tabular}{|c|c|c|c|c|}
\hline Species & Country codes; regions & Climatic zone & Habitat type & Plant traits* \\
\hline Clinopodium vulgare & GB; Berkshire & Atlantic & Calcareous grassland & $\mathrm{p} ; \mathrm{SC} ; \mathrm{sv} ; \mathrm{n} ; \mathrm{h}$ \\
\hline Origanum vulgare & GB; Yorkshire Dales & Atlantic & Calcareous grassland & $\mathrm{p} ; \mathrm{SC} ; \mathrm{sv} ; \mathrm{n} ; \mathrm{hs}$ \\
\hline Primula farinosa & GB; Yorkshire Dales & Atlantic & Limestone grassland & $\mathrm{p} ; \mathrm{SI} ; \mathrm{sv} ; \mathrm{n} ; \mathrm{b}$ \\
\hline Verbascum nigrum & ET; Tartu & Boreal & Gravel pit & b; SI; s; np; hdc \\
\hline Hippocrepis comosa & D; Lower Saxony & Continental & Calcareous grassland & $\mathrm{p} ; \mathrm{SI} ; \mathrm{s} ; \mathrm{np} ; \mathrm{h}$ \\
\hline Ononis masquillierii & I; Bologna & Continental & Roadside, gully & p; SI; sv; po; be \\
\hline Primula veris & D; Lower Saxony & Continental & Calcareous grassland & $\mathrm{p}$; SI; sv; $\mathrm{n}$; hdc \\
\hline Ballota acetabulosa & GR; Lesvos & Mediterranean & Phrygana & $\mathrm{p} ; \mathrm{SI} ; \mathrm{s} ; \mathrm{n}$; be \\
\hline Echium plantagineum & GR; Lesvos & Mediterranean & Phrygana & a; SI; s; n; be \\
\hline Thymus capitatus & GR; Lesvos & Mediterranean & Phrygana & $\mathrm{p} ; \mathrm{SI} ; \mathrm{s} ; \mathrm{n}$; hdc \\
\hline
\end{tabular}

*Life cycle: p, perennial; a, annual; b, biennial; Reproduction: SI, self-incompatible; SC, self-compatible; s, seeds; sv, seeds and vegetative; Reward: n, only nectar; po, only pollen; np, nectar and pollen; Typical pollinators: b, butterflies; bb, bumblebees and butterflies; be, only bees; hs, Hymenoptera and syrphids; h, Hymenoptera; hdc, bees, syrphids, other Diptera and Coleoptera.

plantagineum L.); Lamiaceae (Origanum vulgare L., Clinopodium vulgare L., Thymus capitatus [L.] Hoffmanns \& Link and Ballota acetabulosa [L.] Benth.); Scrophulariaceae (Verbascum nigrum L.); Fabaceae (Hippocrepis comosa L. and Ononis masquillierii Bertol.); Primulaceae (Primula farinosa L. and Primula veris L.).

\section{SELECTION OF PLANT POPULATIONS AND STUDY DESIGN}

For each plant species we selected six to eight populations within a study region, resulting in a total of 74 populations. We operationally defined a population as all flowering plant individuals of the focal species occurring in a habitat fragment. We measured the extent of the area covered by the population ( $p o p A$ ) - which in many cases was equal to the extent of the habitat fragment - using a combination of ground measures and aerial photographs. We directly counted the number of flowering focal plants within the population or extrapolated the number of plants from at least 10 randomly selected subplots in which flowering plants were counted. We were then able to describe the density of the population in terms of number of flowering plants $(p o p D)$. As population area and density varied through the flowering season, we were unable to obtain reliable estimates that could be used as continuous variables. We therefore allocated the populations to two area and two density classes: large versus small and dense versus sparse, respectively (see Table 2). Population area and density vary between the individual plant species and a large area for one species might be smaller than a small area for a different species (Table 2). Due to the choice of very different plant species in very different environments, this was inevitable but does not invalidate the design because the effects of area and density were investigated in their relative rather than absolute terms. As the spatial structure of each plant species- pollinator community pair were characterized by the geographic location (country) and local conditions (topography, soil, climate, land use), which were likely to vary across the pairs' ranges, it was sensible to consider the relative parameters and look for trends within and across each pair. The differences in the absolute values in patch and population size and density were controlled for in the statistical approach chosen (see following text). Populations were selected so that for each plant species all four combinations of the population area and density were included. If possible, populations were at least $2 \mathrm{~km}$ apart to represent independent entities for flower visitors. The overall mean distance $( \pm \mathrm{SD})$ between all populations within a species was $18 \pm 14 \mathrm{~km}$. However, for some species the distances between populations were shorter, e.g. for $O$. masquillierii the minimum distance between populations was $800 \mathrm{~m}$. In such cases independence regarding flower visitors was maintained as the closest populations were separated by dense woodland, which was not crossed by bees (D. Vivarelli personal observation).

Within each population we selected patches of plant individuals (defined as continuous aggregations of the respective plant species) that were separated by at least $2 \mathrm{~m}$ from neighbouring patches. For each patch we measured the area (i.e. extent of the aggregation in $\mathrm{m}^{2}$; pat $A$ ) and density (i.e. the number of flowering plants (inflorescences for H. comosa and T. capitatus) $\mathrm{m}^{-2}$; patD). We ensured that the selection of small and large patches and dense and sparse patches fully covered the available gradient at each location. Exact measurements of area and flower count data at the patch level allowed us to use both pat $A$ and pat $D$ as continuous variables (see Table 2). Again, across species, relative rather than absolute differences in area and density were investigated.

In selecting the patches we tried to avoid the bias of having larger patches in larger populations and denser patches in denser populations. We achieved this for almost all of the plant species, with the exception of O. masquillierii, which had patches in large populations that were significantly larger than in small populations (ANOva: $\left.F_{1,30}=9.71, P<0.01\right)$ and significantly denser in dense populations (anova: $F_{1,30}=5.53, P<0.05$ ). Patch density of $E$. plantagineum was higher in dense populations (ANOva: $F_{1,26}=9.57, P<0.001$ ).

\section{FLOWER VISITATION AND SEED SET}

To estimate flower visitation rates, each patch within each focal population was visited by field researchers trained in pollinator observation. Observations of flower visitation rate to the focal plants were conducted between three and six times in each patch during the main flowering period. In each patch, at each visit one 'observation unit' was selected based on the number of flowers that was feasible to observe (average numbers ranged between 14 for $P$. veris and 306 for $V$. nigrum). Flowers in the observation units were observed for 15 min per observation period and number of flowers visited by potential pollinators was counted (Flower visitation $=$ total number of visits per number of flowers observed per $15 \mathrm{~min}$ ). Observations were only performed under favourable weather conditions in the respective regions. Air temperature during the time of observation was recorded (temp). Observers stayed as far away as possible from the observation unit, remained still for a few minutes before starting 
Table 2. Average values \pm SD of population area $\left(\mathrm{m}^{2}\right)$ and population density (flowers (inflorescences for H. comosa and T. capitatus) $\mathrm{m}^{-2}$ ) and maximum and minimum values of patch area $\left(\mathrm{m}^{2}\right)$ and patch density (flowers (inflorescences for H. comosa and T. capitatus) $\mathrm{m}^{-2}$ ) of the 10 focal plant species. Total number of populations was 74 , of which 28 were large, 46 small, 36 of high density and 38 of low density. Total number of patches was 273

\begin{tabular}{|c|c|c|c|c|c|c|c|c|}
\hline \multirow[b]{2}{*}{ Species } & \multicolumn{2}{|l|}{ Population area } & \multicolumn{2}{|c|}{ Population density } & \multicolumn{2}{|c|}{ Patch area } & \multicolumn{2}{|c|}{ Patch density } \\
\hline & Large & Small & Dense & Sparse & Max & Min & $\operatorname{Max}$ & Min \\
\hline Clinopodium vulgare & $444495 \pm 39350$ & $64646 \pm 112602$ & $0.5 \pm 0.6$ & $0.03 \pm 0.02$ & 445 & 12.0 & 50.5 & 2.3 \\
\hline Origanum vulgare & $17500 \pm 2673$ & $2116 \pm 1805$ & $88.6 \pm 10.7$ & $14.2 \pm 11.1$ & 396 & 0.6 & 118.6 & 2.8 \\
\hline Primula farinosa & $11929 \pm 4337$ & $339 \pm 131$ & $31.9 \pm 4.6$ & $10.3 \pm 4.8$ & 2500 & 0.4 & 35.5 & 0.5 \\
\hline Verbascum nigrum & $86786 \pm 14005$ & $24950 \pm 8758$ & $0.01 \pm 0.003$ & $0.003 \pm 0.001$ & 125 & 3.0 & 6.9 & 0.2 \\
\hline Hippocrepis comosa & $38776 \pm 0$ & $7877 \pm 5477$ & $0.2 \pm 0.2$ & $0.04 \pm 0.03$ & 16 & 0.2 & 625.0 & 162.5 \\
\hline Ononis masquillierii & $4125 \pm 668$ & $450 \pm 341$ & $3.2 \pm 2.4$ & $0.8 \pm 0.2$ & 260 & 0.3 & 116.7 & 1.2 \\
\hline Primula veris & $21959 \pm 11168$ & $2438 \pm 1840$ & $3.6 \pm 2.1$ & $0.4 \pm 0.3$ & 172 & 0.2 & 108.7 & 6.5 \\
\hline Ballota acetabulosa & $13591 \pm 1370$ & $4362 \pm 1510$ & $0.1 \pm 0.1$ & $0.03 \pm 0.01$ & 645 & 16.0 & 1.3 & 0.1 \\
\hline Echium plantagineum & $12645 \pm 6537$ & $2765 \pm 559$ & $9.2 \pm 3.1$ & $0.7 \pm 0.4$ & 216 & 5.2 & 72.3 & 4.3 \\
\hline Thymus capitatus & $2366 \pm 897$ & $542 \pm 287$ & $2.4 \pm 0.2$ & $1.5 \pm 0.5$ & 2630 & 3.8 & 4.6 & 0.4 \\
\hline
\end{tabular}

the observations, and made minimal movements during the observation period.

During the flowering period of each respective plant species, up to 40 plants per population ( $\sim 10$ plants per patch) were chosen at random and two flowers on each plant were selected and marked for pollination treatments. One of the flowers was hand-crossed (as a measure of potential maximum seed set) and the other one was left untreated to be accessed by pollinators. When mature the fruits were harvested and seeds were counted for each individual treatment $(\mathrm{SH}=$ seed set of hand-crossed flowers; $\mathrm{SO}=$ seed set of open-pollinated flowers) to assess the seed set for each treatment. SH was divided by $\mathrm{SO}$ to account for the different maxima in numbers of seeds that a species could produce. We took this ratio of seed sets as a measurement of pollen limitation (PL).

\section{DATA ANALYSES}

To explain flower visitation and seed set in response to the patch and population variables, linear mixed-effects models were fitted with maximum-likelihood estimation (Pinheiro \& Bates 2000). Plant species and population identity were treated as random factors with population being nested within species to account for the nested design of patches within populations and populations within plant species.

We constructed models for eight different subsets of response variables: (i) average flower visitation rate; (ii) mean seed set of all plants (i.e. seed set averaged over number of open-pollinated flowers); (iii) mean seed set of self-incompatible (SI) plant species; and (iv) mean seed set of self-compatible (SC) plant species. Finally, we tested pollen limitation for (v) all plant species; (vi) SI plant species; and (vii) plant species showing an indication of pollen limitation (see following text). Pollen limitation values were log-transformed prior to analysis. We also tested (viii) whether seed set of hand-pollinated flowers responds to any patch or population variable in order to check for non-pollination-related effects on seed set.

Model selection was based on Akaike's second-order Information Criterion $\mathrm{AIC}_{\mathrm{c}}$ for small sample size relative to the number of model parameters (Burnham \& Anderson 2002). We first generated a global model that contained all explanatory variables. The fixed-effect terms incorporated into the global models to predict flower visitation (i) and seed set (ii-viii) were pat A, patD, pop A, popD and their first-order interactions. In a second set of models we substituted pat $D$ with its quadratic term $\left(\right.$ pat $\left.^{2}\right)$ to test for a nonlinear, unimodal response of flower visitation and seed set, respectively, on patch density of flowering plants. In the models for flower visitation, we included the average temperature during observations (temp) and for seed set we added flower visitation. Since absolute values of patch, seed set and flower visitation variables strongly differed among plant species, they were first log-transformed and then standardized separately for each species to have a mean of zero and a standard deviation of one (z-transformation), which facilitated comparison of their effects based on regression coefficients. We then constructed models of all possible subsets of explanatory variables and compared them using $\Delta \mathrm{AIC}_{\mathrm{c}}$ (i.e. difference between $\mathrm{AIC}_{\mathrm{c}}$ for a given model and the best-fitting model) and Akaike weights $w_{\mathrm{i}}$. The latter can be interpreted as the probability that the selected model is the best model of those considered. Models with $\Delta \mathrm{AIC}_{\mathrm{c}}<2$ are considered as being substantially supported by the data and similar in their empirical support to the best model (Burnham \& Anderson 2002).

To estimate the relative importance of explanatory variables $\left(w_{+}(j)\right)$, we summed for each variable (j) the Akaike weight $w_{\mathrm{i}}$ across all models in which the respective variable occurred. Therefore, the larger $w_{+}(j)$, the more important is the variable compared to other variables. The predictive power of the mixed models was assessed by calculating the squared Pearson correlation coefficient between response variable and predicted values from fixed and random effects and from fixed effects only.

Since model comparisons resulted in a number of closely related models, we averaged parameter estimates across models with $\triangle \mathrm{AIC}_{\mathrm{c}}$ $<2$ (Burnham \& Anderson 2002; Johnson et al. 2006). The predictive power of each parameter was estimated by the share in $\Delta R^{2}$ resulting from model predictions where a single term was dropped while the other coefficients remained constant. In the results we present the minimum adequate model, the null model, the global model and the parameter estimates of the averaged models.

Model appropriateness was checked by plotting standardized residuals against fitted values and by normal QQ-plots. All abovementioned statistical analyses were carried out in $R$ (R Development Core Team 2009) using libraries nlme (Pinheiro et al. 2009) and MuMIn (Barton 2009).

A paired $t$-test was used to compare the difference in the seed set of hand- versus open-pollinated flowers for each plant species separately (non-transformed values) to obtain an indication of potential pollen limitation of the plants. This test was calculated with statistica 6.0 for Windows. 


\section{Results}

The predictor variables with the highest relative importance $\left(w_{+}(j)\right)$ for flower visitation of the 10 focal plant species were pat $A$, patD, pop $A$ and temp (Table 3 ). About $54 \%$ of the variation in flower visitation was explained by the models $\left(R^{2}\right.$-fixed + random) whereby about $8 \%$ were only explained by the fixed effects alone ( $R^{2}$-fixed; Table 3$)$; this indicates strong species- and population-specific variation in the data. From the $8 \%$ of variance explained by the fixed effects of the averaged models, the interaction between patD and pop $A$ explained $50 \%$ and temp explained an additional $32 \%$ (Table 3 ). In large populations, increase of pat $D$ had a negative effect on flower visitation, whereas it had a positive effect in small populations (Fig. 1). There was no single best model explaining flower visitation but a total of 11 alternative models gave similar empirical support as the 'best model' (Appendix S1, Supporting Information). Substituting patD by its quadratic term did not improve the predictive power of the models $\left(\mathrm{AIC}_{\mathrm{c}}\right.$ of 'best model' $\left.=728.6 ; w_{\mathrm{i}}=0.04\right)$.

Table 3. The relative importance of predictor variables $w_{+}(j)$ expressed as the sum of Akaike weight across all models calculated to predict flower visitation rate for 10 focal plant species $(n=226)$. The table indicates the Akaike's second-order Information Criterion for small sample size $\left(\mathrm{AIC}_{\mathrm{c}}\right)$, the difference between $\mathrm{AIC}_{\mathrm{c}}$ for a given model and the best-fitting model $\left(\Delta \mathrm{AIC}_{\mathrm{c}}\right)$, the Akaike weight $\left(w_{\mathrm{i}}\right), R^{2}$ values for models containing fixed effects only and both fixed and random effect, and the coefficients (Coeff) of the predictor variables included in the respective models. Coefficients of the model averages are averaged over the 11 candidate models. Further shown are the best candidate model (Best), the null model (Null), the global model (Global) and the model averages for all candidate models with $\triangle \mathrm{AIC}_{\mathrm{c}}$ $<2$ (Avg; $n=11)$. Percentage $R^{2}$ shows the share of the variance the respective predictor variable explains relative to the $R^{2}$ obtained from the averaged coefficients. pat $A=$ patch area; pat $D=$ patch density; pop $A=$ population area; $\operatorname{pop} D=$ population density; temp $=$ temperature during flower observation

\begin{tabular}{lcccccc}
\hline Model & All & Best & Null & Global & Avg & Avg \\
\hline AIC $_{\mathrm{c}}$ & & 727.52 & 729.95 & 736.91 & & \\
$\Delta \mathrm{AIC}_{\mathrm{c}}$ & & 0 & 2.43 & 9.39 & & \\
$w_{\mathrm{i}}$ & & 0.05 & 0.02 & 0.0005 & & \\
$R^{2}$ fixed & & 7.5 & & 9.5 & 8.0 & \\
$R^{2}$ fixed + & & 54.1 & 54.6 & 53.8 & & \\
random & & & & & & \\
& & & & & & \\
\hline Predictor & $w_{(+)}$ & Coeff & Coeff & Coeff & Coeff & $\% R^{2}$ \\
\hline Intercept $)$ & & -0.40 & -0.02 & -0.45 & -0.32 & \\
Temp & 0.61 & 0.12 & & 0.12 & 0.09 & 32.2 \\
pat $A$ & 0.83 & 0.11 & & 0.05 & 0.10 & 4.5 \\
pat $D$ & 0.78 & -0.14 & & -0.23 & -0.10 & 8.0 \\
pop $A$ & 0.73 & 0.03 & & 0.02 & 0.03 & 0.2 \\
popD & 0.55 & & & 0.13 & 0.03 & 2.7 \\
pat $A \times$ patD & 0.25 & & & 0.06 & 0.02 & 2.0 \\
pat $A \times$ pop $A$ & 0.20 & & & 0.08 & 0.01 & 0.1 \\
pat $A \times$ popD $D$ & 0.12 & & & 0.04 & & \\
pat $D \times$ pop $A$ & 0.59 & 0.31 & & 0.41 & 0.24 & 50.4 \\
pat $D \times$ popD $D$ & 0.14 & & & 0.10 & & \\
pop $A \times$ popD & 0.11 & & & 0.06 & & \\
\hline
\end{tabular}

Both patch area and patch density were of equally high relative importance for seed set of open-pollinated flowers and both population variables showed high $w_{+}(j)$ values (Table 4$)$. About $42 \%$ of variation in seed set was explained by the models but again, only $11 \%$ were explained by the fixed effects (Table 4). From the $10.7 \%$ of variance explained by the averaged models, $55.5 \%$ was explained by the interaction between pat $A$ and $\operatorname{pop} A$, and an additional $27 \%$ was explained by the interaction between patD and pop $A$ (Table 4). Seed set is positively affected by increasing pat $A$ in small populations but not in large populations (Fig. 2a). The same applies for the interaction between patD and popA (Fig. 2b). There was no single 'best model' explaining seed set, but instead a total of seven alternative models scored within two points of the lowest AIC value (Appendix $\mathrm{S} 2$ ). All seven alternative models included the interactions pat $A \times p o p A$ and $p a t D \times p o p A$. Interestingly, flower visitation rate was of little importance for seed set (Table 4) and it was only included in three out of the seven alternative models (Appendix S2). Substituting patD by its quadratic term did not improve the predictive power of the models for seed set $\left(\mathrm{AIC}_{\mathrm{c}}\right.$ of 'best model' $=748.2$; $\left.w_{\mathrm{i}}=0.06\right)$.

The model results for seed set of self-incompatible plants were very similar to the results obtained for seed set of all plants. One striking difference was that the effect of patD on seed set of SI plants was independent of popA. In all populations of SI plants, seed set increased with increasing patch density. From the $12 \%$ variance explained by the averaged models $(n=10), 32 \%$ was explained by patD and an additional $57 \%$ was explained by the interaction between pat $A$ and pop $A$. All 10 averaged models contained pat $A$ and pat $D$ and all but one included pop $A$ and the interaction pat $A \times$ popA.

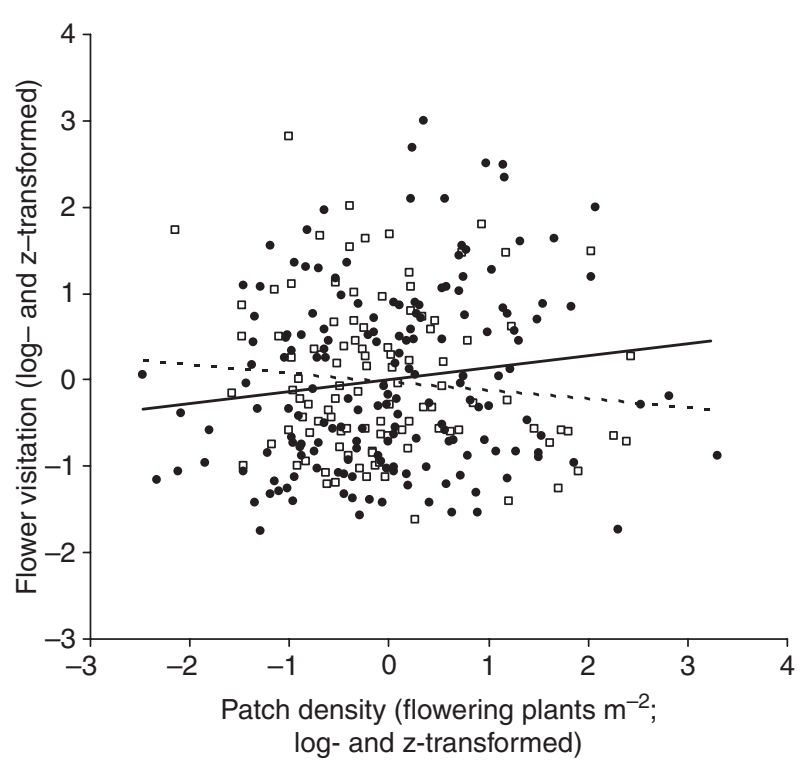

Fig. 1. Flower visitation rate in relation to patch density of 10 focal plant species. Filled dots represent small and open squares large population area. Prediction lines (solid for small and dashed for large population area) were derived from fixed effects of the averaged top models with $\triangle \mathrm{AIC}_{\mathrm{c}}<2$ (see Table 3 ). 
Table 4. The relative importance of predictor variables $w_{+}(j)$ expressed as the sum of Akaike weight across all models calculated to predict seed set of open-pollinated flowers for 10 focal plant species $(n=226)$. The table indicates the Akaike's second-order Information Criterion for small sample size $\left(\mathrm{AIC}_{\mathrm{c}}\right)$, the difference between $\mathrm{AIC}_{\mathrm{c}}$ for a given model and the best-fitting model $(\Delta \mathrm{AIC})$, the Akaike weight $\left(w_{\mathrm{i}}\right), R^{2}$ values for models containing fixed effects only and both fixed and random effect, and the coefficients (Coeff) of the predictor variables included in the respective models. Coefficients of the model averages are averaged over the seven candidate models. Further shown are the best candidate model (Best), the null model (Null), the global model (Global) and the model averages for all candidate models with $\Delta \mathrm{AIC}_{\mathrm{c}}<2(\mathrm{Avg} ; n=7)$. Percentage $R^{2}$ shows the share of the variance the respective predictor variable explains relative to the $R^{2}$ obtained from the averaged coefficients. pat $A$, patch area; pat $D$, patch density; pop A, population area; $p o p D$, population density; Flow. vis., flower visitation rate

\begin{tabular}{|c|c|c|c|c|c|c|}
\hline Model & All & Best & Null & Global & Avg & Avg \\
\hline $\mathrm{AIC}_{\mathrm{c}}$ & & 746.54 & 760.30 & 753.39 & & \\
\hline$\Delta \mathrm{AIC}_{\mathrm{c}}$ & & 0.00 & 13.76 & 6.84 & & \\
\hline & & 0.07 & 0.00007 & 0.002 & & \\
\hline$R^{2}$ fixed & & 11.0 & & 11.5 & 10.7 & \\
\hline $\begin{array}{l}R^{2} \text { fixed }+ \\
\text { random }\end{array}$ & & 41.8 & 43.1 & 42.2 & & \\
\hline Predictor & $w_{(+)} j$ & Coeff & Coeff & Coeff & Coeff & $\% R^{2}$ \\
\hline (Intercept) & & 0.16 & -0.004 & 0.10 & 0.12 & \\
\hline Flow. vis. & 0.45 & & & 0.08 & 0.03 & 1.5 \\
\hline pat $A$ & 0.99 & -0.14 & & -0.13 & -0.07 & 1.3 \\
\hline patD & 0.99 & 0.01 & & 0.07 & 0.02 & -0.3 \\
\hline popA & 0.94 & -0.04 & & 0.03 & -0.03 & 0.1 \\
\hline popD & 0.80 & -0.18 & & -0.11 & -0.13 & 5.6 \\
\hline pat $A \times$ pat $D$ & 0.27 & & & -0.01 & & \\
\hline pat $A \times$ pop $A$ & 0.88 & 0.38 & & 0.37 & 0.35 & 55.5 \\
\hline pat $A \times$ popD & 0.46 & 0.20 & & 0.18 & 0.10 & 9.2 \\
\hline pat $D \times$ pop $A$ & 0.64 & 0.29 & & 0.24 & 0.28 & 27.0 \\
\hline pat $D \times$ pop $D$ & 0.26 & & & -0.08 & -0.01 & 0.2 \\
\hline pop $A \times$ popD & 0.22 & & & -0.14 & & \\
\hline
\end{tabular}

Substituting patD by its quadratic term did not improve the predictive power of the models for seed set of SI plants (patD: $\mathrm{AIC}_{\mathrm{c}}$ of 'best model' $=572.4 ; w_{\mathrm{i}}=0.06 ;$ pat $D^{2}: \mathrm{AIC}_{\mathrm{c}}$ of 'best model' $=574.1 ; w_{\mathrm{i}}=0.06$ ). For the self-compatible plants we could not fit any model that had higher empirical support than the null model.

Separate $t$-tests revealed that seed set was significantly higher in hand-pollinated than in open-pollinated flowers (indicating pollen limitation) in five out of the 10 plant species considered, with all five being SI species (of the eight SI species considered; Table 5). Although not always significant, differences consistently resulted in positive values except for H. comosa.

The degree of pollen limitation could not be explained by any of the variables at the patch or population scale, neither for all species analysed together, nor for the SI species alone, nor for the pollination limited species analysed separately. We could also not fit any model for the seed set of hand-crossed flowers with higher empirical support than the null model.
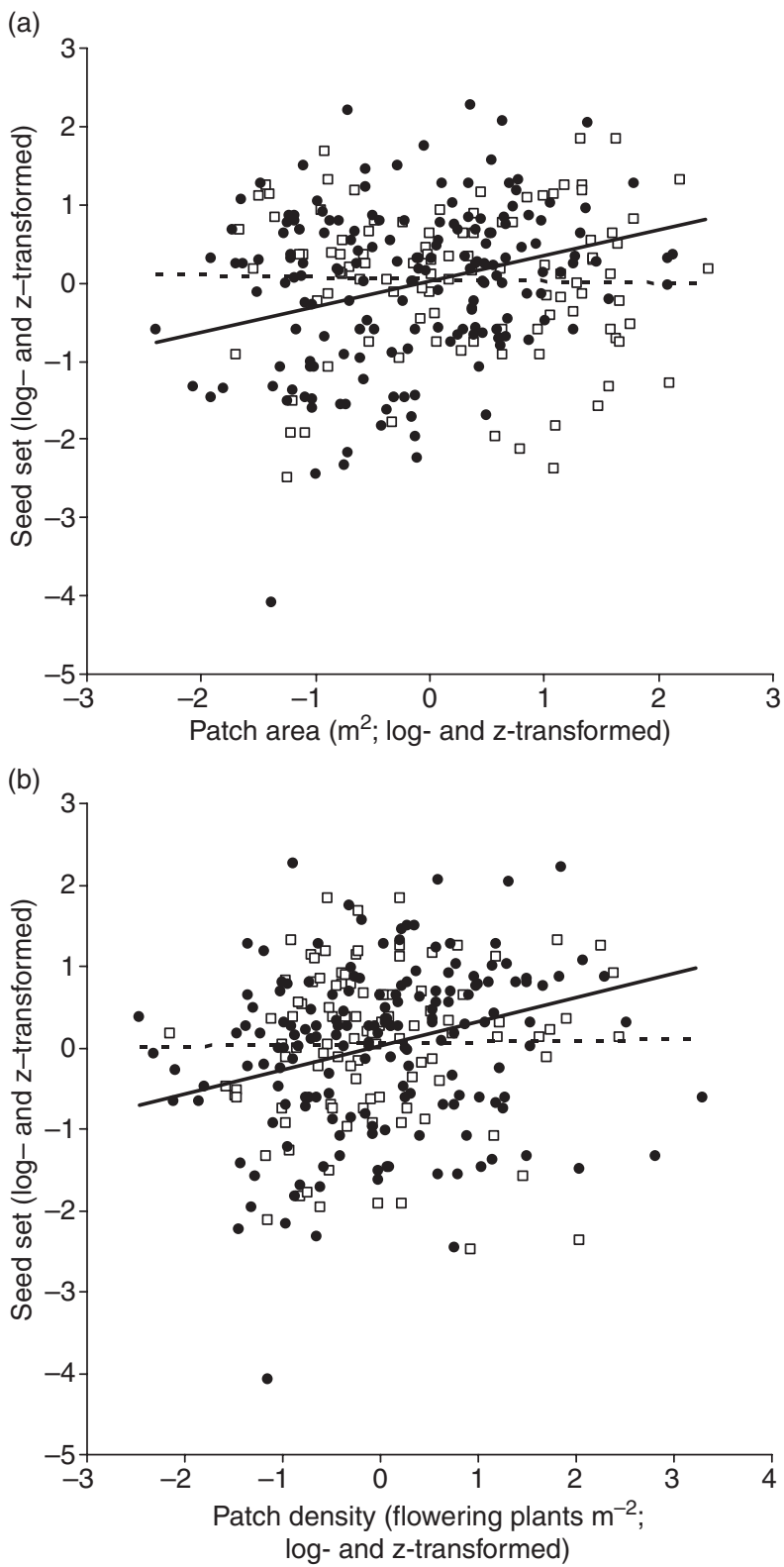

Fig. 2. Seed set of 10 focal plant species in relation to (a) patch area and (b) patch density shown for small (filled dots) and large (open squares) population area. Prediction lines (solid for small and dashed for large population area) derived from fixed effects of the averaged top models with $\Delta \mathrm{AIC}_{\mathrm{c}}<2$ (see Table 4$)$.

\section{Discussion}

In our pan-European study of 10 plant species, we found a general pattern that estimates of pollination success, measured as flower visitation and seed set (cf. Leimu et al. 2006), were related to plant population structure both at the patch and at the population level. Population area showed important interactions with patch density in the models explaining variation in flower visitation rate and with both patch area and density in models explaining seed set of open-pollinated flowers. For both flower visitation and seed set, the effects of patch area and density were only apparent in small populations. 
Table 5. Results of the paired $t$-tests comparing the seed set of handversus open-pollinated flowers (values averaged at the patch level). Diff., mean seed set of hand-pollinated flowers - mean seed set of open-pollinated flowers; SD, standard deviation; $P>0.05=\mathrm{NS}$; $* * P<0.01 ; * * * P<0.001$

\begin{tabular}{lrrrrr}
\hline & Diff. & \multicolumn{1}{l}{ SD } & \multicolumn{1}{c}{$t$} & d.f. & $P$ \\
\hline Echium plantagineum & 1.15 & 0.71 & -8.52 & 27 & $* * *$ \\
Thymus capitatus & 0.75 & 0.36 & -11.79 & 31 & $* * *$ \\
Ballota acetabulosa & 0.22 & 0.17 & -7.22 & 31 & $* * *$ \\
Ononis masquillierii & 0.64 & 0.27 & -13.50 & 31 & $* * *$ \\
Primula veris & 6.91 & 11.08 & -2.86 & 20 & $* *$ \\
Primula farinosa & 1.65 & 15.84 & -0.52 & 24 & NS \\
Hippocrepis comosa & -0.23 & 0.58 & 2.05 & 25 & NS \\
Verbascum nigrum & 0.80 & 6.09 & -0.49 & 13 & NS \\
Origanum vulgare & 0.30 & 0.74 & -2.00 & 23 & NS \\
Clinopodium vulgare & 0.03 & 0.62 & -0.28 & 27 & NS \\
\hline
\end{tabular}

A high plant density within the populations should permit high yields of pollen and nectar for foraging pollinators and lower foraging costs and should again result in high flower visitation rates (Zimmerman 1981; Goulson 2000; Nielsen et al. 2000). In our study, population area and density had an effect but only in interaction with patch variables. Population area was only important for flower visitation in an interaction with patch density, perhaps indicating that there was no resource limitation for pollinators at the population level. The expected lower attractiveness of smaller and sparser plant populations might have been compensated for by co-flowering species within the habitats (Ghazoul 2006; Duffy \& Stout 2008). Unfortunately, this potential explanatory factor could not be tested as data on co-flowering plants were not available.

Rathcke (1983) proposed that visitation rate increases with increasing floral resources at the patch scale until pollinators are saturated by an overabundance of floral resources. A further increase in floral resource availability then potentially leads to a decrease in visitation rates because individual plants start to compete for pollinators (Goulson et al. 1998; Steven et al. 2003). This may have been the case in our large populations, where an increase in flower abundance within a patch led to a decrease in the visitation of individual flowers (Fig. 1). Large patches in large populations could have offered more flowers than the local pollinator community could visit, thereby counterbalancing the benefit of mutual attraction of many conspecific plant individuals (Meyer, Gaebele \& SteffanDewenter 2007). Alternatively, individual pollinators might visit proportionally fewer flowers in large patches, as avoiding already depleted flowers is easier in small patches (Goulson 2000). Moreover, if there are fewer pollinators attracted to small patches, then the rewards are likely to be better per flower and so foragers will tend to remain for longer in these patches, hence visiting a higher proportion of flowers.

The effect of flower visitation rate on seed set had limited empirical support in our study (Table 4). However, we did not expect the relationship between flower visitation and seed set to be straightforward as opposing forces can affect plant reproduction simultaneously. For example, only when the number of pollinators visiting high-density patches is adequate to compensate for the effect of an on average lower flower visitation rate per individual pollinator will seed set increase with patch density (Feldman 2006).

In five out of 10 plant species, our hand-crossing experiment indicated pollen limitation in the open-pollinated flowers. This ratio is below the $62-73 \%$ of plant species showing increased fruit or seed production after pollen supplementation as reported in the review by Ashman et al. (2004). Unfortunately, pollen limitation, measured as the ratio of seed set in handcrossed flowers and open-pollinated flowers, was not explained by the patch and population variables we had studied. These data based on pollen supplementation should be interpreted with caution anyway when used as a basis for measuring pollination deficit (Ashman et al. 2004). For instance, hand crossing a single flower in this context does not necessarily control for resource re-allocation effects and therefore it may not provide a reliable estimate of maximum pollination levels. We also tested the seed set of the hand-crossed flowers to rule out non-pollination-based effects on seed set. Neither patch nor population variables had an effect on seed set of hand-crossed flowers. This confirms that there were no factors involved which might have confounded our intention to use seed set of hand-crossed flowers as a reference for potential pollination limitation effects. Nevertheless, one should not neglect the many other factors contributing to plant fitness, such as breeding system, inter-flower variation, species-specific variation in the composition of the pollinator fauna, as well as patchspecific habitat variation in abiotic factors such as light, water and nutrient availability for individual plants (Fischer, Matthies \& Schmid 1997; Oostermeijer et al. 1998; Shimono \& Washitani 2007). Not having included these factors in our models might therefore explain why the explanatory power of the fixed effects for predicting plant fitness was relatively weak.

Our results are in agreement with the findings of Kéry, Matthies \& Spillmann (2000), Wolf \& Harrison (2001) and Kirchner et al. (2005), i.e. that seed set of plant species in fragmented populations is related to the area and density of patches of flowers within the populations. Even more importantly, our study highlights the interaction of population area with patch area and patch density. The nature of this interaction reveals that the effect of patch area and density is only apparent in small populations. Thus pollen limitation is affected by population structure both at the population and the patch level. The restriction of patch effects on seed set to small populations might be due to differences in flower visitor behaviour and/or community composition in large versus small populations. Many insect pollinators concentrate on one or a few particular plant species they visit during a given foraging bout (Goulson, Ollerton \& Sluman 1997; Goulson \& Wright 1998; Gegear \& Laverty 2005) because floral constancy reduces handling time. Small populations may not contain enough resources to allow for floral constancy, and so pollinators may switch to different species when few target plants are available (Kunin 1993; Petanidou, Den Nijs \& Oostermeijer 1995), leading to heterospecific pollen deposition, which can negatively affect seed set (Wilcock \& Neiland 2002). Increasing patch area and density in small populations 
may compensate for the small number of conspecifics at the population scale by providing enough floral resources to locally ensure pollinator fidelity to the plant species. Focusing on the SI plants among the focal plant species, however, showed a positive effect of patch density on seed set which was independent of population area. Interestingly, the density of flowering plants at the population scale had only minor effects on seed set in our study. This finding differs from that of Kunin (1997b), who found such relationships for formerly common plant species that have become rare due to habitat fragmentation.

The extensive pan-European data set on flower visitation and seed set enabled us to detect general patterns with respect to how the spatial population structure of plants in fragmented habitats affects plant fitness. The difficulty often experienced with data sets that cover a variety of different species sampled in various locations is that random variation or 'noise' in the data may blur the effects under study. In our study, this was evident in the fact that the random effects explained a substantially higher proportion of the variance explanation than did the fixed effects, indicating a strong plant species and population specific response. This should hardly be surprising to any ecologist, as each plant species and site differs in important and interesting ways. Moreover, there was no single best model explaining flower visitation or seed set, respectively, but a relatively high number of alternative models with similar empirical support (see Appendices S1 and S2). However, estimation of optimal parameter values and predictions from multiple models provided us with evidence that the effects of area and density of flowering plant assemblages were in general more pronounced at the patch than at the population level, and that patch and population level together were interacting in shaping the response of plant fitness measures to fragmentation effects. These general patterns can guide our efforts to conserve plantpollinator interactions, ecosystem functioning and host plant populations for pollinators and other interacting species dependent on these plants. The importance of the random effects in our models, however, illustrate that there is still a plant species-specific interplay between the attractiveness of flowering plant patches for pollinators, density dependence of flower visitation and pollinator behavioural responses. This suggests a regionalized and plant-specific targeting of conservation strategies.

\section{Acknowledgements}

This study is part of a Europe-wide assessment of the risks associated with pollinator loss and its drivers, undertaken within the FP 6 Integrated Project 'ALARM' (Assessing LArge scale environmental Risks for biodiversity with tested Methods: GOCE-CT-2003-506675; Settele et al. 2005; http:// www.alarmproject.net). Tiit Teder and Virve Sõber were supported by grant no. 6619 from the Estonian Science Foundation. Mari Moora, Anke Dietzsch, Karl Duffy and two anonymous referees made valuable comments on the manuscript.

\section{References}

Ågren, J. (1996) Population size, pollination limitation, and seed set in the selfincompatible herb Lythrum salicaria. Ecology, 77, 1779-1790.
Aguilar, R., Ashworth, L., Galetto, L. \& Aizen, M.A. (2006) Plant reproductive susceptibility to habitat fragmentation: review and synthesis through a meta-analysis. Ecology Letters, 9, 968-980.

Aizen, M.A. \& Feinsinger, P. (1994) Habitat fragmentation, native insect pollinators, and feral honey-bees in Argentine Chaco Serrano. Ecological Applications, 4, 378-392.

Ashman, T.L., Knight, T.M., Steets, J.A., Amarasekare, P., Burd, M., Campbell, D.R., Dudash, M.R., Johnston, M.O., Mazer, S.J., Mitchell, R.J., Morgan, M.T. \& Wilson, W.G. (2004) Pollen limitation of plant reproduction: ecological and evolutionary causes and consequences. Ecology, 85, 2408-2421.

Barton, K. (2009) MuMIn: multi-model inference. R package version 0.12.2. http://r-forge.r-project.org/projects/mumin/.

Burnham, K.P. \& Anderson, D.R. (2002) Model Selection and Multimodel Inference: A Practical Information-Theoretic Approach. Springer-Verlag, New York.

Campbell, L.G. \& Husband, B.C. (2007) Small populations are mate-poor but pollinator-rich in a rare, self-incompatible plant, Hymenoxys herbacea (Asteraceae). New Phytologist, 174, 915-925.

Cunningham, S.A. (2000) Effects of habitat fragmentation on the reproductive ecology of four plant species in mallee woodland. Conservation Biology, 14, 758-768.

Duffy, K.J. \& Stout, J.C. (2008) The effects of plant density and nectar reward on bee visitation to the endangered orchid Spiranthes romanzoffiana. Acta Oecologica, 34, 131-138.

Feldman, T.S. (2006) Pollinator aggregative and functional responses to flower density: does pollinator response to patches of plants accelerate at low-densities? Oikos, 115, 128-140.

Fischer, M., Matthies, D. \& Schmid, B. (1997) Response of rare calcareous grassland plants to elevated $\mathrm{CO}_{2}$ : a field experiment with Gentianella germanica and Gentiana cruciata. Journal of Ecology, 85, 681-691.

Fischer, M. \& Stöcklin, J. (1997) Local extinctions of plants in remnants of extensively used calcareous grasslands 1950-1985. Conservation Biology, 11, 727-737.

Fox, L.R. (2007) Climatic and biotic stochasticity: disparate causes of convergent demographies in rare, sympatric plants. Conservation Biology, 21, $1556-1561$.

Gegear, R.J. \& Laverty, T.M. (2005) Flower constancy in bumblebees: a test of the trait variability hypothesis. Animal Behaviour, 69, 939-949.

Ghazoul, J. (2006) Floral diversity and the facilitation of pollination. Journal of Ecology, 94, 295-304.

Goulson, D. (2000) Why do pollinators visit proportionally fewer flowers in large patches? Oikos, $\mathbf{9 1}, 485-492$.

Goulson, D., Ollerton, J. \& Sluman, C. (1997) Foraging strategies in the small skipper butterfly, Thymelicus flavus: when to switch? Animal Behaviour, 53, 1009-1016.

Goulson, D. \& Wright, N.P. (1998) Flower constancy in the hoverflies Episyrphus balteatus (Degeer) and Syrphus ribesii (L.) (Syrphidae). Behavioral Ecology, 9, 213-219.

Goulson, D., Stout, J.C., Hawson, S.A. \& Allen, J.A. (1998) Floral display size in comfrey, Symphytum officinale L. (Boraginaceae): relationships with visitation by three bumblebee species and subsequent seed set. Oecologia, 113, 502-508.

Hegland, S.J. \& Totland, Ø. (2008) Is the magnitude of pollen limitation in a plant community affected by pollinator visitation and plant species specialisation levels? Oikos, 117, 883-891.

Holland, J.N. \& Chamberlain, S.A. (2007) Ecological and evolutionary mechanisms for low seed:ovule ratios: need for a pluralistic approach? Ecology, 88, 706-715.

Jakobsson, A., Padron, B. \& Traveset, A. (2008) Pollen transfer from invasive Carpobrotus spp. to natives - A study of pollinator behaviour and reproduction success. Biological Conservation, 141, 136-145.

Jennersten, O. (1988) Pollination in Dianthus deltoides (Caryophyllaceae): effects of habitat fragmentation on visitation and seed set. Conservation Biology, 2, 359-366.

Jennersten, O. \& Nilsson, S.G. (1993) Insect flower visitation frequency and seed production in relation to patch size of Viscaria vulgaris (Caryophyllaceae). Oikos, 68, 283-292.

Johnson, M.D., Thomas, W.S., Holmes, R.T. \& Marra, P.P. (2006) Assessing habitat quality for a migratory songbird wintering in natural and agricultural habitats. Conservation Biology, 20, 1433-1444.

Kareiva, P. \& Wennergren, U. (1995) Connecting landscape patterns to ecosystem and population processes. Nature, 373, 299-302.

Kearns, C.A., Inouye, D.W. \& Waser, N.M. (1998) Endangered mutualisms: the conservation of plant-pollinator interactions. Annual Review of Ecology and Systematics, 29, 83-112. 
Kéry, M., Matthies, D. \& Spillmann, H.H. (2000) Reduced fecundity and offspring performance in small populations of the declining grassland plants Primula veris and Gentiana lutea. Journal of Ecology, 88, 17-30.

Kirchner, F., Luijten, S.H., Imbert, E., Riba, M., Mayol, M., Gonzalez-Mart1nez, S.C., Mignot, A. \& Colas, B. (2005) Effects of local density on insect visitation and fertilization success in the narrow-endemic. Centaurea corymbosa (Asteraceae) Oikos, 111, 130-142.

Klinkhamer, P.G.L. \& van der Lugt, P.-P. (2004) Pollinator service only depends on nectar production rates in sparse populations. Oecologia, $\mathbf{1 4 0}$ 491-494.

Knight, T.M., Steets, J.A., Vamosi, J.C., Mazer, S.J., Burd, M., Campbell, D.R., Dudash, M.R., Johnston, M.O., Mitchell, R.J. \& Ashman, T.L. (2005) Pollen limitation of plant reproduction: pattern and process. Annual Review of Ecology Evolution and Systematics, 36, 467-497.

Krauss, J., Steffan-Dewenter, I. \& Tscharntke, T. (2003) How does landscape context contribute to effects of habitat fragmentation on diversity and population density of butterflies? Journal of Biogeography, 30, 889900.

Kunin, W.E. (1993) Sex and the Single Mustard: population density and pollinator behavior effects on seed-set. Ecology, 74, 2145-2160.

Kunin, W.E. (1997a) Population biology and rarity: on the complexity of density-dependence in insect-plant interactions. The Biology of Rarity: Causes and Consequences of Rare-Common Differences (eds W.E. Kunin \& K.J. Gaston), pp. 150-173, Chapman \& Hall, London.

Kunin, W.E. (1997b) Population size and density effects in pollination: pollinator foraging and plant reproductive success in experimental arrays of Brassica kaber. Journal of Ecology, 85, 225-234.

Larson, B.M.H. \& Barrett, S.C.H. (2000) A comparative analysis of pollen limitation in flowering plants. Biological Journal of the Linnean Society, 69 , 503-520.

Leimu, R., Mutikainen, P., Koricheva, J. \& Fischer, M. (2006) How general are positive relationships between plant population size, fitness and genetic variation? Journal of Ecology, 94, 942-952.

Meyer, B., Gaebele, V. \& Steffan-Dewenter, I. (2007) Patch and landscape effects on pollinator diversity and seed set of Hippocrepis comosa in an agricultural landscape. Entomologia Generalis, 30, 173-185.

Murphy, S.D. \& Aarssen, L.W. (1995) Reduced seed set in Elytrigia repens caused by allelopathic pollen from Phleum pratense. Canadian Journal of Botany, 73, 1417-1422.

Nielsen, A. \& Ims, R.A. (2000) Bumble bee pollination of the sticky catchfly in a fragmented agricultural landscape. Ecoscience, 7, 157-165.

Nielsen, L.R., Philipp, M., Adsersen, H. \& Siegismund, H.R. (2000) Breeding system of Scalesia divisa Andersson, an endemic Asteraceae from the Galapagos islands. Det Norske Vitenskaps akademi. I. Matematisk Naturvitenskaplig Klasse, Skrifter, Ny Serie, 39, 127-138.

Oostermeijer, J.G.B., Luijten, S.H., Krenova, Z.V. \& Den Nijs, J.C.M. (1998) Relationships between population and habitat characteristics and reproduction of the rare Gentiana pneumonanthe L. Conservation Biology, 12, 1042 1053.

Oostermeijer, J.G.B., Luijten, S.H., Petanidou, T., Kos, M., Ellis-Adam, A.C \& Den Nijs, H.C.M. (2000) Pollination in rare plants: is population size important? Det Norske Vitenskaps akademi. I. Matematisk Naturvitenskaplig Klasse, Skrifter, Ny Serie, 39, 201-213.

Petanidou, T., den Nijs, H. \& Ellis-Adam, A. (1991) Comparative pollination ecology of two rare Dutch Gentiana species in relation to population size. Acta Horticulturae, 288, 308-312.

Petanidou, T., Den Nijs, J.C.M. \& Oostermeijer, J.G.B. (1995) Pollination ecology and constraints on seeds et of the rare perennial Gentiana cruciata L. in the Netherlands. Acta Botanica Neerlandica, 44, 55-74.

Petanidou, T., Ellis-Adam, A.C., den Nijs, H.C.M. \& Oostermeijer, J.G.B. (1998) Pollination ecology of Gentianella uliginosa, a rare annual of the Dutch coastal dunes. Nordic Journal of Botany, 18, 537-548.

Pinheiro, J.C. \& Bates, D.M. (2000) Mixed-Effect Models in $S$ and S-PLUS Springer, New York.

Pinheiro, J., Bates, D., DebRoy, S., Sarkar, D. \& the R Core team (2009) nlme: linear and Nonlinear Mixed Effects Models. R package version 3.1-92. http://cran.r-project.org/web/packages/nlme/index.html.

R Development Core Team (2009) $R:$ A Language and Environment for Statistical Computing. The R Foundation for Statistical Computing, Vienna, Austria.
Rathcke, B. (1983) Competition and facilitation among plants for pollination. Pollination Biology (ed. L. Real), pp. 305-329, Academic Press, Orlando.

Rosenzweig, M.L. (1995) Species Diversity in Space and Time. Cambridge University Press, Cambridge, UK.

Settele, J., Hammen, V., Hulme, P., Karlson, U., Klotz, S., Kotarac, M. et al. (2005) ALARM - Assessing LArge-scale environmental Risks for biodiversity with tested Methods. GAIA-Ecological Perspectives for Science and Society, 14, 69-72.

Shimono, A. \& Washitani, I. (2007) Factors affecting variation in seed production in the heterostylous herb Primula modesta. Plant Species Biology, 22, $65-76$

Steffan-Dewenter, I., Münzenberg, U. \& Tscharntke, T. (2001) Pollination, seed set and seed predation on a landscape scale. Proceedings of the Royal Society of London Series B-Biological Sciences, 268, 1685-1690.

Steffan-Dewenter, I. \& Tscharntke, T. (1999) Effects of habitat isolation on pollinator communities and seed set. Oecologia, 121, 432-440.

Steffan-Dewenter, I. \& Tscharntke, T. (2002) Insect communities and biotic interactions on fragmented calcareous grasslands - a mini review. Biological Conservation, 104, 275-284.

Steffan-Dewenter, I., Klein, A.-M., Alfert, T., Gaebele, V. \& Tscharntke, T. (2006) Bee diversity and plant-pollinator interactions in fragmented landscapes. Plant-pollinator Interactions: from Specialization to Generalization (eds N.M. Waser \& J. Ollerton), pp. 387-407, University of Chicago Press, Chicago.

Steven, J.C., Rooney, T.P., Boyle, O.D. \& Waller, D.M. (2003) Density-dependent pollinator visitation and self-incompatibility in upper Great Lakes populations of Trillium grandiflorum. Journal of the Torrey Botanical Society, 130, 23-29.

Vitousek, P.M. (1994) Beyond global warming - ecology and global change. Ecology, 75, 1861-1876.

Waites, A.R. \& Ågren, J. (2004) Pollinator visitation, stigmatic pollen loads and among-population variation in seed set in Lythrum salicaria. Journal of Ecology, 92, 512-526.

Waser, N.M. (1983) Adaptative nature of floral traits. Pollination Biology (ed. L. Real), pp. 242-285, Academic Press, Orlando.

Westphal, C., Steffan-Dewenter, I. \& Tscharntke, T. (2003) Mass flowering crops enhance pollinator densities at a landscape scale. Ecology Letters, $\mathbf{6}$, 961-965.

Wilcock, C. \& Neiland, R. (2002) Pollination failure in plants: why it happens and when it matters. Trends in Plant Science, 7, 270-277.

Wolf, A.T. \& Harrison, S.P. (2001) Effects of habitat size and patch isolation on reproductive success of the Serpentine Morning Glory. Conservation Biology, 15, 111-121.

Zimmerman, M. (1981) Patchiness in the dispersion of nectar resources: probable causes. Oecologia, 49, 154-157.

Received 31 July 2009; accepted 11 September 2009

Handling Editor: Roy Turkington

\section{Supporting Information}

Additional Supporting Information may be found in the online version of this article:

Appendix S1. Ranking of candidate models derived from the global model for flower visitation rate.

Appendix S2. Ranking of candidate models derived from the global model for seed set of open-pollinated flowers.

As a service to our authors and readers, this journal provides supporting information supplied by the authors. Such materials may be re-organized for online delivery, but are not copy-edited or typeset. Technical support issues arising from supporting information (other than missing files) should be addressed to the authors. 